\title{
Use of Rice Husk Ash Blended Cement to Produce Cement Sand Blocks: Optimal Level of Cement Replacement for Compressive Strength
}

\author{
D. A. R. Dolage, K. Mylvaganam, P. Mayoorathan and S. Inparatnam
}

\begin{abstract}
This article primarily investigates the variation in compressive strength, in relation to different levels of replacement of cement with rice husk ash (RHA) when blended cement is used to produce cement sand blocks. The samples of RHA used in this study have been obtained directly from furnaces and were not further incinerated. This study considers two binder-sand ratios (1:3 and 1:6), three water-binder ratios $(0.4,0.5$ and 0.6$)$ in its attempt to determine the optimum level of cement replacement. The study determines that at around five percent level of replacement the compressive strength exceeds that of unblended cement. The compressive strength developed when cement replacement level is 15 percent, is greater than that stipulated in SLS 855: Part 1:1989 (2.5MPa) for cement sand blocks. The study also concludes following: disregarding the level of replacement, the compressive strength steadily decreases when cement replacement levels exceed the limit of five percent; of the three water-binder ratios, 0.5 offers marginally higher compressive strengths than the other two ratios; compressive strength does not vary when cubes cast using RHA samples obtained from three districts are tested; the development in compressive strength when samples are matured beyond 28days till 60 days is only 19 percent. Finally, the study concludes that given all RHA generated in the country can be put in the use for cement replacement, the total saving to the country is approximately Rs. billion 2.25 .
\end{abstract}

Key words: Rice husk ash, Blended cement, Concrete, Pozzolanic action, Compressive strength

\section{Introduction}

In Sri Lanka, the cost of manufacturing of cement based material has been gradually increasing owing to the cost of cement. This is primarily due to the high cost of energy needed in cement production. In view of this, it is important to economise the use of Ordinary Portland Cement (OPC) by confining its use to situations where higher strengths are anticipated.

Rice husk which is the outer covering of the rice grain is an agricultural by product generated in the rice milling process. It constitutes 20 percent of the mass of the paddy (Ganesan et al. 2008). Sri Lanka recorded its highest ever paddy production of 3.87 million metric tons in 2008 (Central Bank 2008). Incidentally, the total paddy production in 2009 declined by 5.8 percent to 3.65 million metric tons (Central Bank 2009). Nonetheless, the paddy production in Sri Lanka is bound to increase further in time to come with the development work envisaged in North and Eastern provinces.
In Sri Lanka, rice husk generated as a raw material is predominantly used within the rice milling process as the primary energy source for parboiling of paddy. Also substantial quantity of rice husk is burnt in open heap village burning method at a temperature ranging from $300^{\circ} \mathrm{C}$ to $450^{\circ} \mathrm{C}$, as a way of disposal. This uncontrolled burning is often considered as the most cost-effective disposal method for rice husk ash not only in Sri Lanka but also in India. This seasonal and highly localised massive burning generates excessive air pollution that invariably lowers air quality in the environment. When the husk is converted to ash by uncontrolled burning below $500^{\circ} \mathrm{C}$, the incineration is not completed and considerable amount of unburnt carbon is

Eng.(Dr.) D.A.R. Dolage, BSc Eng. (Moratuwa),CEng, FIE(Sri Lanka), MSc (Reading), MA (Colombo), MBA (SJP), DBA (UniSA), Senior Lecturer, Department of Civil Engineering, The Open University of Sri Lanka.

K. Mylvaganam, BTech (Eng), The Open University of Sri Lanka.

P. Mayoorathan, Undergraduate, Department of Civil Engineering, The Open University of Sri Lanka

S. Inparatnam, Undergraduate, Department of Civil Engineering, The Open University of Sri Lanka 
left in the resulting ash (Ganesan et al. 2008). Carbon content in excess of 30 percent was expected to have an adverse effect on pozzolanic activity of RHA (Cook 1986). The ash produced by controlled burning of the rice husk between $550^{\circ} \mathrm{C}$ to $700^{\circ} \mathrm{C}$ incinerating temperature for one hour transforms the silica content of the ash into amorphous phase (Boating and Skeete 1990).

This research paper investigates the use of RHA which contains pozzolanic amorphous silica component in forming blended cement in order to produce cement sand blocks. Also it attempts to determine the optimal level of cement replacement to attain a satisfactory level of compressive strength for cement sand blocks.

\section{Literature review}

RHA is a pozzolan which when properly burnt has high $\mathrm{SiO}_{2}$ content and can be used as a concrete admixture. A pozzolan is a material which, when combined with calcium hydroxide, exhibits cementitious properties. RHA exhibits high pozzolanic characteristics and contributes to high strength and high impermeability of concrete. Pozzolanic materials are siliceous or siliceous and aluminous materials, which in themselves possess little or no cementitious value, but will, in finely divided form and in the presence of moisture, chemically react with calcium hydroxide liberated on hydration, at ordinary temperature, to form compounds, possessing cementitious properties (Shetty, 2005). Pozzolans play an important role when added to Portland cement because they usually increase the mechanical strength and durability of concrete structures (Isaia et al., 2003). According to Shetty (2005), Pozzolanic materials can be divided into two groups: natural pozzolana (Clay and Shales, Opalinc Cherts, Diatomaceous Earth, Volcanic Tuffs and Pumicites) and artificial pozzolana (Fly ash, Blast furnace slag, Silica fume, Risk Husk Ash, Metakaoline, Surkhi).

The type of RHA suitable for the pozzolanic action is amorphous rather than crystalline ash. It has been adequately proven that the silica in the ash undergoes structural transformations under varies temperature conditions. The Pozzolanic reaction primarily occurs between amorphous siliceous materials (namely, pozzolan) and slaked lime (calcium hydroxide) to form calcium silicate hydrates. The chemistry of rice husk ash cement involves the chemical reactions of the amorphous silica in the ash with lime to form calcium silicate hydrates (ElDakroury and Gasser 2008). At the basis of the pozzolanic reaction stands a simple acid-base reaction between calcium hydroxide, also known as Portlandite, or $\left(\mathrm{Ca}(\mathrm{OH})_{2}\right)$, and silicic acid $\left(\mathrm{H}_{4} \mathrm{SiO}_{4}\right.$, or $\left.\mathrm{Si}(\mathrm{OH})_{4}\right)$. The silicates formed are of the kinds CSHI and CSHII. According to Boating \& Skeete (1990), the reaction may be illustrated as:

$$
\mathrm{Ca}(\mathrm{OH})_{2}+\mathrm{SiO}_{2}=\mathrm{CSHI}+\mathrm{CSHII}
$$

Where

$$
\begin{aligned}
& \mathrm{CSHI}=\mathrm{CaO}_{1.5-2.0} \mathrm{SiO}_{2}\left(\mathrm{H}_{2} \mathrm{O}\right)_{1.0-2.5}
\end{aligned}
$$

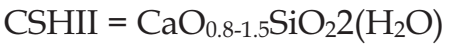

The product of general formula, $\mathrm{CaH}_{2} \mathrm{SiO}_{4} \cdot 2$ $\mathrm{H}_{2} \mathrm{O}$ formed is a calcium silicate hydrate, also abbreviated as CSH in cement chemist notation. As the density of CSH is lower than that of portlandite and pure silica, a consequence of this reaction is a swelling of the reaction products. This reaction may also occur with time in concrete between alkaline cement pore water and poorly-crystalline silica aggregates. This delayed process is also known as alkali silica reaction, or alkali-aggregate reaction, and may seriously damage concrete structures because the resulting volumetric expansion is also responsible for spalling and decrease of the concrete strength.

Ganesan et al. (2008), undertook a study to assess the optimal level of replacement for strength and permeability properties of concrete produced using RHA blended cement. In this study, experiments were carried out in two phases as per standard test procedures. In the first phase, the tests to determine chemical composition, physical properties and characterization of RHA were carried out. This also included tests for evaluation of standard consistency, initial setting time, final setting time and compressive strength of RHA blended cements. In the second phase, tests were carried out on compressive strength, splitting tensile strength, water absorption, coefficient of water absorption, sorptivity, resistance to chloride ion penetration and diffusion coefficient. The significant feature of this study is that the rice husk residue that was fired uncontrollably was collected from mills and placed in the furnace.

The controlled combustion of rice husk is so important that studies have been dedicated to 
investigate the use of new techniques. In such a study, Nehdi et al. (2003) developed a new technology for the production of RHA, based on a Trobed reactor that facilitated producing highly reactive RHA with much lower carbon content than that of RHA produced using fluidized beds. The RHA produced using the new technique required less grinding time than that produced in a fluidised bed and also did not substantially increase the water demand and the super plasticizer requirement.

There are evidences to the fact the research institutes in Sri Lanka had the desire and commitment to exploit the RHA use for industrial purposes. In 1988, Ceylon Institute of Scientific and Industrial Research (CISIR) compiled a report on industrial uses of rice husk ash in Sri Lanka (CISIR, 2005). The Report recommends the use of RHA as a suitable building material due to its cementitious properties. Much later, in 1999, the Research and Development Centre of Institute of Post Harvest Technology (IPHT) compiled a report on Rice Husk availability and consumption pattern in Sri Lanka (IPHT 1999). The report concluded that an average of $48 \%$ of rice husk produced by the mills is used as a fuel for steam generation and the rest is discarded; one way of discarding is through open heap burning.

In a research carried out in Sri Lanka (Bandara (1994) investigated the following: the critical firing temperature and the isothermal firing time (soaking period) for different varieties of rice husk available locally; the factors favourable for the formation of active silica present in the ash fired in the laboratory furnace and relate these conditions with the field trials in order to improve the efficiency of the production of ash under field conditions. The study concludes that firing temperature and isothermal firing time for attaining high amount of amorphous silica in fired ash depends on the variety of rice husk ash. The study also reveals that, as an approximation, a firing temperature of $700^{\circ} \mathrm{C}$ seems to be the optimum for the four Sri Lankan varieties of rice husk ash examined in the study; an isothermal firing time of 30 to 60 minutes is to be adopted based on the knowledge of the variety of rice husk. According to the study, compressive strength of mortar cubes of five blended cement compositions showed low early strength developments as compared to those of OPC control mortar; the compositions 40:60 and 35:65 (RHA:OPC) were the most favourable blends in terms of strength development. However, in this study, RHA obtained from rice mills were further incinerated in an electric muffle furnace at temperatures varying from $500^{\circ} \mathrm{C}$ to $800^{\circ} \mathrm{C}$ for durations of 30 minutes and one hour. Further incineration of RHA obtained from rice mills using furnaces operated electrically or otherwise is, obviously, a costly affair and such costs may not warrant the use of RHA as a pozzolan.

The foregoing discussion explains that it is pertinent to conduct a study in order to investigate pozzolanic characteristics of untreated RHA in terms of; strength development in relation to time; optimal level of cement replacement for compressive strength. As the initial step, use of untreated RHA in cement mortar is investigated prior to that in concrete since the strength requirement in mortar cubes is not as crucial as that in concrete.

\section{Methods and Materials}

\subsection{Materials used}

The OPC conforming to Sri Lankan standard SLS 107: Part 12008 was utilised in preparing the binder. Graded river sand passing through $2.36 \mathrm{~mm}$ sieve with fineness modulus of 2.83 (between sieve sizes of $5 \mathrm{~mm}$ and 160 micro meters and specific gravity of 1.6 was used as fine aggregate. The RHA samples were obtained from boiler furnaces from three rice mills located in three different districts namely Vavuniya, Ampara and Batticaloe. At the each location, the samples were collected from three places of the heap which were later mixed in order to make it more representative. Since the samples contained fired rice husk ash that had been bunt in an uncontrolled way they were black in colour, obviously, due to the presence of excessive amount of carbon content. The RHA obtained in this manner was not further burnt in laboratory furnace. Such untreated RHA was used in preparing cement mortar cubes needed for testing.

\subsection{Physical analysis of OPC and RHA}

Particle size distribution of OPC and RHA was determined through particle size analyser. Specific surface area of OPC was measured as per SLS 107 Part 2: 2008 using Blain's air permissibility apparatus. Other important 
physical properties such as specific gravity, bulk density and fineness of OPC and RHA were evaluated as per SLS 107 Part 2: 2008.

\subsection{Blended cements}

RHA blended cements were prepared by replacing OPC with different amount of RHA $(0 \%, 5 \%, 10 \%$ and $15 \%$ by weight of cement) in dry condition. The mixtures were thoroughly homogenised and kept in sealed containers.

\subsection{Compressive strength of blended cement mortar cubes}

The compressive strength of RHA blended cement mortar cubes having uniform size of $100 \times 100 \times 100 \mathrm{~mm}$, in binder-sand ratios of $1: 3$ and 1:6 and in water-binder ratios of $0.4,0.5$ and 0.6 was determined after 7,28 and 60 days of moisture curing as per SLS 107 Part 2: 2008.

\subsection{Mix proportions and casting of mortar specimens}

It was decided to go for four different cement replacement levels in preparing the blended cement, where the proportion of RHA ranging from $0 \%, 5 \%, 10 \%$ and $15 \%$ by weight of cement. The $0 \%$ RHA by weight of cement was the control sample which was adopted for comparative purposes. The replacement of cement with RHA was made by weight in order to circumvent possible errors due to the low specific gravity of RHA. The research programme adopted two, binder-sand mix proportions namely 1:3 and 1:6. For each of the resulting eight different mix proportions, three further mix combinations were prepared using water-binder ratios namely, $0.4,0.5$ and 0.6. Accordingly, 24 different mortar mix combinations were prepared and from each mix proportion six cubes were cast; two cubes for each test of compressive strength at 7 days, 28 days and 60 days. This resulted in casting of $192(2 \times 4 \times 3 \times 2 \times 3=144)$ mortar cubes.

The RHA and cement were mixed thoroughly to form a homogeneous blend which in turn was mixed with fine aggregates. A measured quantity of water (based on the water-binder ratio) was added to this mixture and was mixed thoroughly with a shovel until it reaches the required workability. Then the mixture was placed in a mould of size $100 \times 100 \times 100 \mathrm{~mm}$ in three layers; each layer was compacted with a $16 \mathrm{~mm}$ diameter MS rod with 25 blows. Soon after casting, each mortar cube was labelled so that they can be easily identified later. After 24 hours, the specimens were demoulded and kept in a water bath for 7 days or 28 days or 60 days, depending on the period after which test is to be performed. The test for compressive strength of the mortar cubes was performed at the specific time using the $2000 \mathrm{kN}$ compression testing machine.

Additional set of $54(3 \times 3 \times 2 \times 3=54)$ cement mortar cubes) were cast in order to test if there was any variation in compressive strength when RHA obtained from different geographical areas were used. The test cubes were prepared only for the mix proportion 1:6 binder-sand ratio and water-binder ratio of 0.5.

\section{Results and Discussion}

\subsection{Physical analysis of OPC and RHA}

The particle size distribution (PSD) curves of OPC and RHA are shown in Figure 1. The particles of RHA are nearly four times coarser than those of OPC and are well graded in their distribution. Table 1 depicts the Physical properties of both OPC and RHA. The bulk density, specific gravity and mean grain size of RHA are found to be greater than those of OPC.

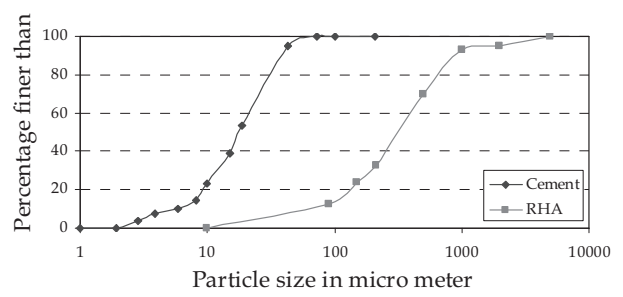

Figure 1: Particle size distribution curves of cement and RHA

\subsection{Compressive strength of blended cement mortar cubes}

The compressive strength of RHA blended cement mortars are shown in Table 2. The main objective of the study is to determine the suitability of use of RHA in making cement sand blocks. The use of 1:3 binder-sand ratio which invariably and bound to produce greater compressive strength for the requirement is also expensive. In this research, the tests were performed for both these mix proportions in order for the better comparison of values. A simple scanning over Table 2 is enough to say that binder-sand ratio of 1:3 produces 
significantly higher values for compressive strength than that for 1:6. Therefore, in the analysis of compressive strengths of mortar cubes made using different binder-cement ratios, it is justifiable to place a greater emphasis on the results obtained for the bindercement ratio of $1: 6$ due to the practical significance.

The increase in compressive strength with the passage of time, for a given mortar mix, is gradual. For instance, according to Table 2, for binder-sand ratio of 1:6, water-binder ratio 0.5 and a cement replacement level of $5 \%$, the compressive strengths at 7 days, 28 days and 60 days in MPa are 5.20, 5.45 and 6.10 respectively. Hence, the analysis of compressive strengths of different combinations is limited to compressive strength obtained for samples tested for 60 days after curing.
4.2.1 Influence of cement replacement levels and water-binder ratios

Figures 2 and 3 depict variation in compressive strength of mortar cubes in $\mathrm{MPa}$ in relation to cement replacement levels for binder-sand ratios of 1:3 and 1:6 respectively. Each figure shows the said variation for the samples made in the three different waterbinder ratios namely $0.4,0.5$ and 0.6. According to the graphs, the influence of water-binder ratio on the compressive strength of cement sand blocks is significantly low; this is true for both bindersand ratios namely 1:3 and 1:6.

Table 1-Physical properties of OPC and RHA

\begin{tabular}{|l|l|l|l|l|l|}
\hline Materials & $\begin{array}{l}\text { Bulk Density } \\
\left(\mathrm{g} / \mathrm{cm}^{3}\right)\end{array}$ & $\begin{array}{l}\text { Specific } \\
\text { gravity }\end{array}$ & $\begin{array}{l}\text { Fineness passing } \\
45 \mu \text { sieve }\end{array}$ & $\begin{array}{l}\text { Specific surface } \\
(\text { Blain's })\left(\mathrm{m}^{2} / \mathrm{kg}\right)\end{array}$ & $\begin{array}{l}\text { Mean grain size } \\
(\mu \mathrm{m})\end{array}$ \\
\hline OPC & 1.80 & 1.3 & 96 & 340 & 22.5 \\
\hline RHA & 1.86 & 2.1 & 7.5 & - & 42.0 \\
\hline
\end{tabular}

Table 2-Mix proportion and compressive strength of RHA blended cement mortars

\begin{tabular}{|c|c|c|c|c|c|c|}
\hline \multirow{2}{*}{$\begin{array}{l}\text { Mix proportion } \\
\text { (Binder/Sand) }\end{array}$} & \multirow{2}{*}{$\begin{array}{l}\text { Water/ } \\
\text { Binder } \\
\text { ratio }\end{array}$} & \multicolumn{2}{|c|}{ Mix proportions } & \multicolumn{3}{|c|}{ Compressive strength (MPa) } \\
\hline & & $\mathrm{OPC}(\%)$ & RHA (\%) & 7 days & 28 days & 60 days \\
\hline \multirow[t]{12}{*}{$1: 3$} & \multirow[t]{4}{*}{0.4} & 100 & 0 & 11.50 & 11.90 & 13.75 \\
\hline & & 95 & 5 & 10.20 & 13.25 & 15.60 \\
\hline & & 90 & 10 & 4.05 & 4.40 & 5.10 \\
\hline & & 85 & 15 & 2.70 & 3.45 & 4.25 \\
\hline & \multirow[t]{4}{*}{0.5} & 100 & 0 & 12.00 & 12.35 & 15.00 \\
\hline & & 95 & 5 & 11.60 & 13.60 & 16.85 \\
\hline & & 90 & 10 & 4.75 & 5.25 & 5.65 \\
\hline & & 85 & 15 & 2.95 & 4.00 & 4.70 \\
\hline & \multirow[t]{4}{*}{0.6} & 100 & 0 & 12.00 & 12.10 & 15.70 \\
\hline & & 95 & 5 & 11.25 & 12.65 & 16.55 \\
\hline & & 90 & 10 & 4.60 & 5.00 & 5.50 \\
\hline & & 85 & 15 & 2.75 & 3.50 & 3.75 \\
\hline \multirow[t]{12}{*}{$1: 6$} & \multirow[t]{4}{*}{0.4} & 100 & 0 & 4.25 & 5.50 & 5.65 \\
\hline & & 95 & 5 & 4.30 & 5.20 & 5.90 \\
\hline & & 90 & 10 & 2.50 & 3.25 & 4.00 \\
\hline & & 85 & 15 & 1.25 & 1.50 & 2.65 \\
\hline & \multirow[t]{4}{*}{0.5} & 100 & 0 & 4.50 & 5.20 & 5.70 \\
\hline & & 95 & 5 & 5.20 & 5.45 & 6.10 \\
\hline & & 90 & 10 & 2.90 & 4.00 & 4.50 \\
\hline & & 85 & 15 & 1.35 & 2.65 & 2.95 \\
\hline & \multirow[t]{4}{*}{0.6} & 100 & 0 & 4.25 & 5.15 & 6.50 \\
\hline & & 95 & 5 & 4.90 & 5.25 & 5.75 \\
\hline & & 90 & 10 & 2.75 & 3.75 & 4.30 \\
\hline & & 85 & 15 & 1.25 & 1.75 & 2.70 \\
\hline
\end{tabular}


Although the variation of compressive strength in relation to 'cement replacement levels' is somewhat similar to the three water binder ratios, the magnitude of the compressive strength is higher for bindersand ratio 1:3 than for 1:6. With respect to both binder-sand ratios 1:3 and 1:6, cement replacement level of $5 \%$ produces the highest compressive strength.

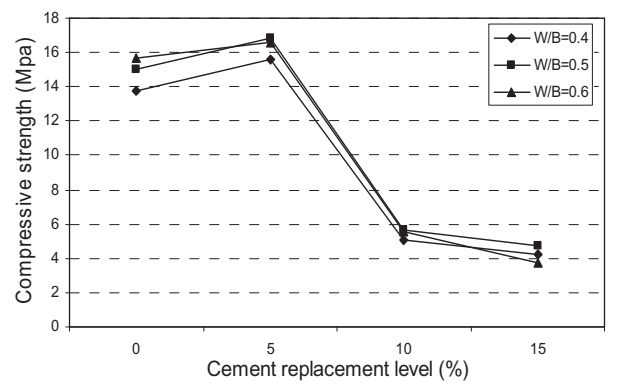

Figure 2-Compressive strength variation in relation to cement replacement levels (cement- binder ratio 1:3)

The figures also show that when cement replacement level gradually increases beyond $5 \%$ the compressive strength steadily decreases.

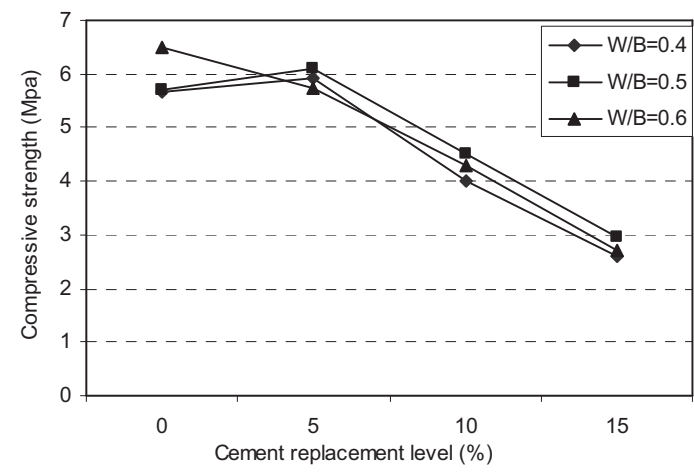

Figure 3-Compressive strength variation in relation to cement replacement levels (binder-sand ratio 1:6)

It is important to closely examine the variation in compressive strength at a given cement replacement level with respect to the three water-binder ratios. Figures 4 and 5 represent, for different cement replacement levels, the compressive strength in relation to different waterbinder ratios for binder-sand ratios 1:3 and 1:6 respectively. The highest compressive strength is shown at the $5 \%$ cement replacement level when the water-binder ratio is 0.5. The highest values for compressive strength are observed for samples cured for 60 days, at $5 \%$ cement replacement level which are $16.85 \mathrm{MPa}$ and 6.10 MPa for binder-sand ratios 1:3 and !:6 respectively. Another notable observation is that when cement replacement level is $15 \%$, disregarding the magnitude of waterbinder ratio, compressive strength reaches very low values such as $4.70 \mathrm{MPa}$ and 2.95 MPa for binder-sand ratios of 1:6 and 1:3 respectively. Moreover, it is observed that the variation in compressive strength in relation to water-binder ratios $(0.4,0.5$ or $0.6)$ for a given cement replacement level is not significant, for both binder-sand ratios.

Figure 6 shows the variation of compressive strength of mortar cubes in relation to different cement replacements levels, for a given water-binder ratio. According to the figure, the pattern of variation of compressive strength in relation to cement replacement level is similar for all three water-binder ratios. Hence, it can be deduced that pattern of compressive strength variation is not dependent on the water-binder ratio.

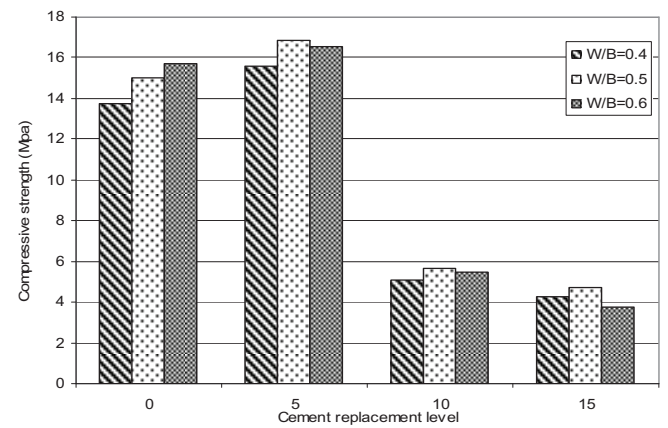

Figure 4 - Compressive strength variation in relation to cement replacement levels and water-binder ratio (binder-sand ratio 1:3)

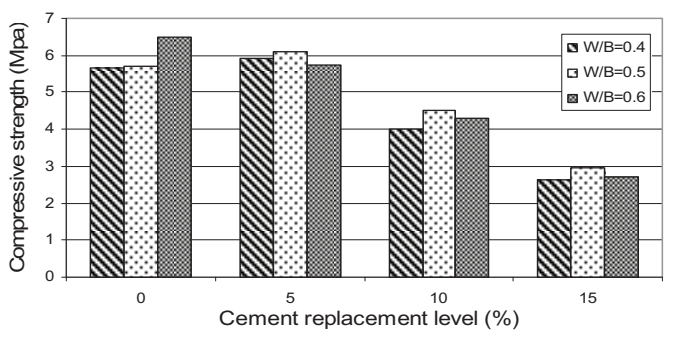

Figure 5 - Compressive strength variation in relation to cement replacement levels and water-binder ratio (binder-sand ratio 1:6) 


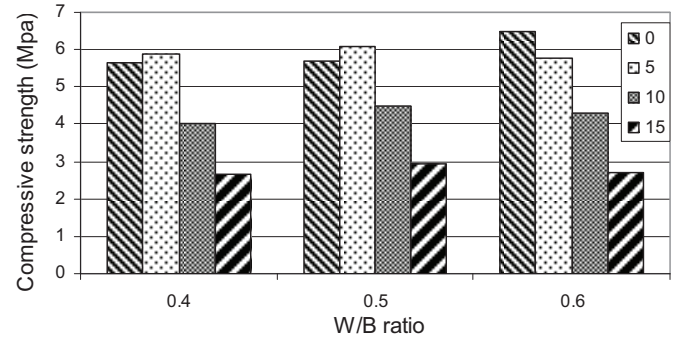

Figure 6-Compressive strength variation in relation to water-binder ratio

In research studies (Ganesan et al. 2008 \& Bandara 1994) conducted to investigate the compressive strength of concrete or mortar made with binders where RHA is used to replace cement, the development of strength in relation to age is a major consideration. Figure 7 shows the variation in compressive strength with respect to age of mortar in days, for different cement replacement levels. According to Figure 7, for untreated RHA the development of compressive strength for $0 \%$ cement replacement (or $100 \%$ cement) and for 5\% cement replacement levels (or 95\% cement) is very much similar. The gain in compressive strength between 7 days and 60 days is $1.2 \mathrm{MPa}$ and $0.9 \mathrm{MPa}$ for replacement levels $0 \%$ and $5 \%$ respectively. However, for cement replacement levels of $10 \%$ and $15 \%$, the compressive strengths show a rapid rate of growth. The gain in compressive strength between 7 days and 60 days is $1.6 \mathrm{MPa}$ for both cement replacement levels $10 \%$ and $15 \%$. Further, 7 days compressive strength for $5 \%$ cement replacement level is very much higher than those for both cement replacement levels of $10 \%$ and $15 \%$.

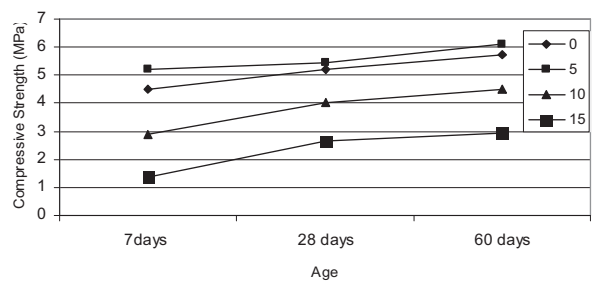

Figure 7- Compressive strength variation in relation to age

Therefore, in situations where higher replacement levels of RHA are adopted this low initial compressive strength has to be considered. The Figure 7 also shows very clearly that by adding RHA by $5 \%$, its compressive strength can be increased more than that produced with $100 \%$ cement which is a significant finding of the study. The average 28 days and 60 days compressive strength of mortar cubes are 6.25 MPa and 7.46 MPa respectively. This indicates the increase in compressive strength over the period 28 days to 60 days is $19 \%$ which is relatively a marginal increase.

The compressive strengths when cement replacement level is $15 \%$, water binder-ratio is 0.5 and binder-sand ratio is 1:6 are 2.65 and 2.95 for ages 28 days and 60 days respectively. According to Sri Lanka Standard 855: Part 1:1999 (Specifications for Cement Blocks Part 1_ Requirements), the compressive strength required of solid cement-sand blocks for a single storey and two storeys for mortar designation (cement -sand) $1: 5$ or $1: 8$ are 1.2 and $2.5 \mathrm{MPa}$ respectively. Hence, it can be said that a cement replacement level of $15 \%$, water binder-ratio of 0.5 and binder-sand ratio of 1:6 affords a suitable mix specification for cement sand blocks to be used for single or two story buildings. Also it can be deduced that in the use of blended cement, for the same requirement, the optimal level of cement replacement is $15 \%$.

\subsubsection{Variation in compressive strength in mortar made with RHA geographically}

Table 3 depicts the results obtained for the compressive strength of mortar cubes cast using the RHA obtained from the three geographic areas namely Batticaloa, Ampara Vavuniya. For the purpose of comparison, if we consider compressive strengths at 60 days, at 5\% cement replacement level (for binder: sand ratio of $1: 6$ and water-binder ratio of 0.5 ) for the three areas Batticaloa, Ampara and Vavuniya are 6.10, 5.90 and $6.00 \mathrm{MPa}$ respectively. This indicates that the variation in compressive strength of mortar cubes cast with blended cement of which RHA obtained from different areas is not significant.

\subsubsection{Cost Analysis}

In year 2009, the annual paddy production in Sri Lanka is 3.65 million metric tons 
Annual rice husk production in Sri Lanka is $3.65 \times 0.20$ million metric tons which means 0.73 million metric tons; assuming husk forms $20 \%$ of paddy grain in weight.

Annual RHA production in Sri Lanka is $0.73 \times 0.20$ which means 0.146 million metric tons; assuming husks when burnt reduces in weight to $20 \%$ of husk weight

Table 3 - Compressive strength of samples of Obtained of Different Districts

\begin{tabular}{|l|l|l|l|l|l|}
\hline District & \multicolumn{2}{|c|}{$\begin{array}{c}\text { Mix } \\
\text { proportions }\end{array}$} & \multicolumn{3}{c|}{$\begin{array}{c}\text { Compressive } \\
\text { strength (MPa) }\end{array}$} \\
\cline { 2 - 6 } & $\begin{array}{l}\text { OPC } \\
\text { (\%) }\end{array}$ & $\begin{array}{l}\text { RHA } \\
\text { (\%) }\end{array}$ & $\begin{array}{l}\mathbf{7} \\
\text { days }\end{array}$ & $\begin{array}{l}\mathbf{2 8} \\
\text { days }\end{array}$ & $\begin{array}{l}\mathbf{6 0} \\
\text { days }\end{array}$ \\
\hline \multirow{3}{*}{$\begin{array}{l}\text { Battical } \\
\text { oa }\end{array}$} & 95 & 5 & 5.20 & 5.45 & 6.10 \\
\cline { 2 - 6 } & 90 & 10 & 2.90 & 4.00 & 4.50 \\
\cline { 2 - 6 } & 85 & 15 & 1.35 & 2.65 & 2.95 \\
\hline \multirow{3}{*}{$\begin{array}{l}\text { Ampary } \\
\text { a }\end{array}$} & 95 & 5 & 5.10 & 5.25 & 5.90 \\
\cline { 2 - 6 } & 90 & 10 & 2.70 & 4.10 & 4.35 \\
\cline { 2 - 6 } & 85 & 15 & 1.65 & 2.95 & 3.25 \\
\hline \multirow{2}{*}{ Vavuni } & 95 & 5 & 5.40 & 5.05 & 6.00 \\
\cline { 2 - 6 } ya & 90 & 10 & 2.30 & 4.30 & 4.40 \\
\cline { 2 - 6 } & 85 & 15 & 1.75 & 2.80 & 3.25 \\
\hline
\end{tabular}

Binder:Sand $=1: 6$ and Water: Binder $=0.5$

Since one metric ton is $1000 \mathrm{~kg}$, RHA produced in a year is 146 million $\mathrm{kg}$. Alternatively, the equivalent number of $50 \mathrm{~kg}$ bags RHA that can be produced are $2,920,000$ bags. In a scenario where complete stock of RHA is usable as an alterative material, the possible saving for the country is Rs. $775 x \quad 2,920,000=$ Rs.2,263,000,000. The price of cement is assumed to be Rs.775. Hence, provided that widespread availability of RHA can be attained, the gross savings for national economy is approximately Sri Lankan rupees 2.25 billion. Nevertheless, the net savings would be somewhat less since the analysis has excluded the packaging, transportation and handling charges for RHA.

The number of $300 \times 150 \times 100 \mathrm{~mm}$ cement sand blocks that can be produced with one bag of cement, without blending of RHA is 60. The number of $300 \times 150 \times 100 \mathrm{~mm}$ cement sand blocks that can be produced with one bag of cement, using RHA in the blend is 69; assuming RHA percentage in binder is $15 \%$. This indicates that with one bag of cement additional 9 cement sand blocks can be manufactured. This example can convince, of course in a rudimentary manner, those in areas where people have access to RHA, blending RHA in cement is a viable and economical option.

\section{Conclusions}

(1) Rice husk ash obtained from rice mills, as it is, can be blended with cement in order to manufacture cement sand blocks. For any given combination, when cement replacement level increases from $0 \%$ to $5 \%$ the compressive strength gradually increases and thereafter steadily decreases.

(2) The binder-sand ratio of $1: 6$ is satisfactory and has compressive strengths of $2.65 \mathrm{MPa}$ and $2.95 \mathrm{MPa}$ for an age of 28 days and 60 days respectively. The minimum strength specified in the SLS 107 Part 2: 2008 for cement sand blocks is 2.5 MPa. Hence, cement replacement level 15\% is the optimum for making cement sand blocks.

(3) The influence of water-binder ratio on the comprehensive strength, particularly within the range of 0.4 to 0.6 is found to be marginal.

(4)The increase in compressive strength over the period from 28days until 60 days is only 19 percent which is only a marginal increase. This indicates compressive strengths reaches a satisfactory level within a short period.

(5) The development of compressive strength for both cement replacement levels of $10 \%$ and $15 \%$ is slower than that for either $0 \%$ (only cement in the binder) or $5 \%$.

(6) The variation of compressive strength of mortar cubes cast with RHA obtained from districts Batticalo, Ampara and Vavuniya, among the districts is almost negligible. This implies a similarity in the degree of incineration of paddy husks at mills and the types of paddy grown in these areas.

(7) The total quantity of RHA produced in Sri Lanka is estimated to be 146 million kg; or alternatively a number of 2,920,000, fifty kilogramme bags. In a scenario where all the RHA can be put into use the total gross 
saving to the national economy is Rs 2.25 billion.

(8) At the moment rice mill owners have been compelled to destroy rice husk by open heap burning. This process depletes the oxygen quantity in the air and so environmentally very hazardous. Hence, it is a colossal damage to the society if RHA so produced, at a tremendous cost to the environment, not put into productive use. If the demand for RHA increases as expected rice mill owners can adopt technologically advanced furnaces which help to incinerate rice husk at controlled conditions.

\section{Acknowledgement}

The authors wish to express their gratitude to Holcim (Lanka) Ltd. for testing physical properties of RHA.

\section{References}

1 Bandara, D.H.M.S., “Development of Blended Cement Utilizing the Pozzolanic Amorphous Silica Component of Rice Husk Ash", Journal of National Science Council, 1994 22(2):189-199.

2. Boating, A.A. and Skeete, D.H., "Incineration of Rice Hull for use as a Cementations Materials; The Gayana Experience." Cement Concrete Research, 1990; 20; 795-802.

3. Central Bank Annual Report 2009, Central Bank of Sri Lanka, Colombo Sri Lanka.

4. Central Bank Annual Report 2008, Central Bank of Sri Lanka, Colombo Sri Lanka.

5. Ceylon Institute of Scientific and Industrial Research "Report on Industrial Use of Rice Hull Ash", CISIR, Colombo 1988.

6. Cook, J.D., Rice Husk Ash, In: Swamy $\mathrm{RN}$, editor, Concrete Technology and Design. Cement Replacement Materials, Vol 3, London: Surrey University Press; 1986, pp.171-95.
7. El-Darkroury, A., Gasser M.S., “Rice husk ash (RHA) as Cement Admixture for Immobilisation of liquid Radioactive Waste at Different Temperatures," Journal of Nuclear Materials, 381 (2008) 271-277.

8. Gaesan K., Rajagopal, K, Thangavel, K., "Rice Husk ash Blended Cement: Assessment of Optimal level of Replacement for Strength and Permeability Properties of Concrete", Journal of Construction and Building Materials, 22, 2008, pp.1675-1683.

9. Institute of Post Harvest Technology Research and Development Center, Report on Paddy Husk Availability and Consumption Pattern in Sri Lanka, IPHTRDC, Anuradapura, Sri Lanka, 1999.

10. Isaia, G.C., Gastaldini, A. L, Moraes, G. R, Physical and Pozzolanic Action of Mineral additions on the Mechanical Strength of High-Performance, Journal Cement and Concrete Composites, Volume 25, Issue 1, January 2003, Pages 69-76.

11. Nehdi, M, Duquette, J., El Damatty, A., Performance of Rice Husk Ash Produced using a New Technology as a Mineral Admixture in Concrete, Journal of Cement and Concrete Research, 33, 2003 1203-1210.

12. Shetty, M.S., Concrete Technology, $8^{\text {th }}$ edn. S. Chand \& Company Ltd, Ram Nagar, New Delhi, 2005.

13. Sri Lanka Standard 107: Part 1: 2008 (Specifications for Ordinary Portland Cement-Requirements).

14. Sri Lanka Standard 107: Part 2 1:2008 (Specifications for Ordinary Portland Cement-Test Methods).

15. Sri Lanka Standard 855: Part 1:1999 (Specifications for Cement Blocks Part 1_ Requirements).

16. Sri Lanka Standard 855: Part 1:1999 (Specifications for Cement Blocks Part 1_Test Methods). 
